\title{
ANALYSIS OF PREPAREDNESS FOR THE IMPLEMENTATION OF SIMPLIFIED SYSTEM AND PERMISSION PROCESS IN THE DEVELOPMENT OF MEDICAL DEVICES
}

\author{
Pritha Elisa'), Dumilah Ayuningtyas²) \\ 1)Masters Program in Public Health, Universitas Indonesia \\ ${ }^{2)}$ Health Policy and Administration Department, Faculty of Public Health, \\ Universitas Indonesia
}

\begin{abstract}
Background: In the health national insurance (JKN) era, the need for medical devices was fulfilled by more than 90\% of imported products. Therefore, the government issued the Minister of Health Regulation No. 17 of 2017 concerning the action plan for the development of the pharmaceutical industry and medical devices. This study aimed to determine the preparedness for the implementation of simplified system and permission process in the development of medical devices.

Subjects and Method: This was a qualitative study conducted in July 2019. The key informants were officials from the ministry of health directorate of medical devices and household health supplies evaluation and supervision. The informants were also people from the Indonesian Association of Medical Device Manufacturers. The study theme was preparedness for the implementation of simplified system and permission process in the development of medical devices. The study variables included the size and objective of the policy, resource, characteristics of the implementing agency, communication between organization, disposition of implementer, as well as the social, economic, and political environment. The data were collected through in-depth interview and observation and analyzed descriptively.

Results: Preparedness for the implementation of simplified system and permission process in the development of medical devices based on Minister of Health Regulation No. 17 of 2017 was quite good. The size and objectives of the implementation policy were clear enough. The available resources were sufficient and qualified. Standard operational procedure (SOP) had been prepared and applied to the system. Policy communication had gone well. Implementer disposition in addressing policies was optimal. The economic, social and political environment had a significant influence on policy implementation.

Conclusion: Preparedness for the implementation of simplified system and permission process in the development of medical devices has been running well in terms of variable size and policy objective, resource, implementing agency characteristic, communication between organization, implementing disposition, and the social, economic, and political environment.
\end{abstract}

Keywords: medical device, licensing, implementation, policy, domestic

\section{Correspondence:}

Pritha Elisa. Masters Program of Public Health, Faculty of Public Health, Universitas Indonesia, Depok, West Java, Indonesia. Email: pritha.elisa@gmail.com Mobile: 085692877460 . 